\title{
Insulin Injection Knowledge, Attitudes, and Practices of Nurses in China: A Cross-Sectional Nationwide Study
}

\author{
Xinjuan $\mathrm{Wu}$ (D) - Fang Zhao $\cdot$ Mingxia Zhang $\cdot$ Li Yuan · \\ Yining Zheng $\cdot$ Jin Huang $\cdot$ Yangxi Li $\cdot$ Caihong Li
}

Received: May 28, 2021 / Accepted: July 16, 2021 / Published online: August 4, 2021

(C) The Author(s) 2021

\begin{abstract}
Introduction: To evaluate insulin injection knowledge, attitudes, and practices of nurses across China in order to provide reference for the formulation of a national unified standard of insulin injection practice and the targeted implementation of standardized training on insulin injection for nurses.
\end{abstract}

Xinjuan $\mathrm{Wu}$ and Fang Zhao contributed equally to this work.

Supplementary Information The online version contains supplementary material available at https:// doi.org/10.1007/s13300-021-01122-x.

\section{$\mathrm{X} . \mathrm{Wu}(\bowtie)$}

Department of Nursing, Peking Union Medical College Hospital, Chinese Academy of Medical Sciences and Peking Union Medical College, Beijing 100730, China

e-mail: wuxinjuan@sina.com

F. Zhao

Department of Nursing, China-Japan Friendship Hospital, Beijing 100029, China

\section{Zhang}

Department of Endocrinology, Peking University People's Hospital, Beijing 100044, China

L. Yuan

Department of Endocrinology and Metabolism, West China School of Nursing, West China Hospital of Sichuan University, Sichuan University, Chengdu 610041, China
Methods: We enrolled nurses who worked and injected insulin at grassroot hospitals including community health service centers and township clinics, secondary and tertiary care hospitals across China between July 28, 2019 and August 30, 2019. A nurse insulin injection knowledge, attitude, and practice questionnaire was used to evaluate the knowledge, attitude, and practice level of nurses.

Results: A total of 223,368 nurses were included in the study. The mean knowledge score was $13.70 \pm 3.30$ and $35.19 \%$ had a poor knowledge score. The mean attitude score was $17.18 \pm 2.69$ for the study nurses; merely $3.15 \%$ had a poor attitude score. The mean practice score of the study population was $83.03 \pm 8.16$

\section{Y. Zheng}

Beijing Friendship Hospital, Capital Medical

University, Beijing 100050, China

\section{J. Huang}

Clinical Nursing Teaching and Research Section/ Department of Metabolism and Endocrinology, The Second Xiangya Hospital of Central South University, Changsha 410011, China

\section{Y. Li}

Respiratory Center, China-Japan Friendship Hospital, Beijing 100029, China

\section{C. $\mathrm{Li}$}

Department of Endocrinology, School of Clinical Medicine, Beijing Tsinghua Changgung Hospital, Tsinghua University, Beijing 102218, China 
and only $0.88 \%$ had a poor practice score. Pearson correlation analysis showed significant correlation between the knowledge score and the attitude score $(r=0.29 ; \quad P<0.001)$, the knowledge score and the practice score $(r=0.27 ; P<0.001)$, and between the attitude score and the practice score $(r=0.56$; $P<0.001)$. A multivariate analysis revealed that nurses with higher knowledge scores were also more likely to have higher attitude scores and practice scores, and nurses with higher attitude scores were also more likely to have higher practice scores.

Conclusion: Chinese nurses have a good attitude and behavior towards insulin injection, while their knowledge of insulin injection is insufficient. It is also revealed that knowledge of insulin injection can directly or indirectly affect insulin injection behavior through attitude, indicating that hospitals should formulate unified insulin injection norms and regularly organize relevant training and assessment so as to improve nurses' knowledge, attitude, and behavior of insulin injection.

Keywords: Knowledge; Attitudes; Practices; Insulin injection

\section{Key Summary Points}

Numerous studies have demonstrated that a sizeable proportion of nurses still lack proper insulin injection knowledge, have not skillfully mastered insulin injection techniques, and should be compliant with insulin injection guidelines.

This is the first cross-sectional study of insulin injection knowledge, attitude, and practice among nurses at different healthcare settings across China.

The study highlights the need for workplace-based learning and training to further enhance insulin injection-related knowledge, attitude, and practice.

\section{INTRODUCTION}

The global prevalence of diabetes has rapidly increased over the past decade [1] and close to 600 million people are predicted to develop diabetes by 2035 globally [2]. Diabetes also poses a major public health burden in China; according to the International Diabetes Federation (IDF) report, China has the highest number of patients with diabetes in the world [3] 2019. Patients with type 1 diabetes (T1DM) are absolutely deficient in insulin and must rely on exogenous insulin supplementation. Insulin treatment is also required for patients with type 2 diabetes (T2DM) with progressive $\beta$-cell insufficiency or who are contraindicated for oral antidiabetic medications.

Insulin intensification therapy is often used in hospitalized patients in and outside endocrinology departments. Proper insulin injection knowledge and practices are critical to blood glucose control in both patients with T1DM and patients with T2DM. Many of the issues in insulin injection practices by nurses can be attributed to their inadequate knowledge of proper insulin injection techniques, suggesting the importance of educating the nurses on proper insulin injection techniques and improving their compliance with insulin injection guidelines [4, 5]. Numerous studies have demonstrated that a sizeable proportion of nurses still lack proper insulin injection knowledge, have not skillfully mastered insulin injection techniques, and have not been compliant with insulin injection guidelines [6-10]. However, no cross-sectional study across China has been conducted and no study has been conducted in a primary care setting in China.

In the current cross-sectional, non-interventional nationwide study, we sought to evaluate insulin injection knowledge, attitudes, and practices of nurses and nurse administrators who had performed insulin injection within the preceding year at primary, secondary, and tertiary care hospitals across China using the stratified sampling method. 


\section{METHODS}

\section{Study Population}

This cross-sectional, non-interventional multicenter study conducted at multiple centers across China (Appendix I in the supplementary material) enrolled nurses who worked and injected insulin at grassroot hospitals including community health service centers and township clinics, secondary and tertiary care hospitals between July 28, 2019 and August 30, 2019. Nurses who provided at least one insulin injection within the preceding year were eligible. Nurses in training, interns, and nursing students were excluded. Nurses were randomly chosen from 231 grassroot hospitals, $453 \mathrm{sec}$ ondary care hospitals, and 564 tertiary care hospitals listed on the Chinese government's official website [11]. Data on gender, age, years worked, professional title, and administrative title were retrieved.

The study protocol ethical approval was granted by the ethics committee of China-Japan Friendship Hospital (No. 2019-68-K47), the leading institution for the study, and local ethics committees and institutional review boards of the participating institutions (Appendix I in the supplementary material). All study subjects provided written informed consent prior to enrollment. The study was conducted in accordance with the Declaration of Helsinki.

\section{Questionnaire}

The nurse insulin injection knowledge, attitude, and practice questionnaire asked the participants about their knowledge about insulin, injection technique, and hypoglycemia prevention and treatment, their attitudes regarding importance, standardization, and confidence of insulin injection technique, and their practices in the use of insulin injection devices and injection procedure. The questionnaire was designed on the basis of the Guidelines for Drug Administration Techniques in Diabetes Patients in China 2016 Guidelines on Chinese Diabetes Medication Skills [10] with two rounds of consultation with 17 experts on the China Diabetes Expert Committee and Chinese Nursing Association Nursing Management Committee. The questionnaire was pretested and validated in nurses of three hospitals in China. Construct validity was tested to estimate the validity of our instrument. Cronbach's $\alpha$ was 0.686 for the nurse insulin injection knowledge domain, 0.785 for the insulin injection attitude domain, and 0.886 for the insulin injection practice domain, indicating excellent internal consistency. In the nurse insulin injection knowledge domain, items $1,2,6,16$, and 19-21 were related to mastery of basic knowledge, items 3-5 were related to mastery of insulin storage knowledge, and items $7-15,17$, and 18 related to mastery of insulin injection techniques. Each item had a score of 1 for correct answer and the total score was 21. A total score less than 13 was considered poor, a score $\geq 13$ but $<17$ was considered satisfactory and a score $\geq 17$ was considered good. In the insulin injection attitude domain, items 1-4 were assigned a score 1-5 for the choices given in the order given and items 5 and 6 were not assigned a score. The total score was 20 . A total score less than 12 was considered poor, a score $\geq 12$ but $<16$ was considered satisfactory, and a score $\geq 16$ was considered good. In the insulin injection practice domain, items 1-14 and 16-18 were assigned a score $1-5$ for the choices given in the order given and item 15 was assigned a score $5-1$ for the choices given in the order given. The total score was 90 . A total score less than 54 was considered poor, a score $\geq 54$ but $<72$ was considered satisfactory, and a score $\geq 72$ was considered good. The questionnaire was administered between January 1, 2019 and February 28, 2019 via the website portal http://ww.wjx.cn and answered anonymously by participants using laptop computer, mobile phone, and smart devices.

\section{Statistical Analysis}

Statistical analysis was carried out using SAS9.3 (The SAS Institute, Cary, NC, USA). Quantitative data were presented as mean \pm standard deviation or median (interquartile range, IQR) 
and compared by Student's $t$ test or Wilcoxon rank sum test, when appropriate. All categorical data were presented as percentage and compared by chi-square analysis. The correlation among knowledge, altitude, and practices was analyzed using Spearman correlation. In addition, score levels and correlation coefficients were analyzed using the Cochran-Mantel-Haenszel (CMH3) method. Poor knowledge, altitude, and practices were entered into multivariate linear logistic regression analysis as dependent variables and nurse characteristics as independent variables. A $P$ value less than 0.05 in a two-sided test or the OR 95\% CI did not cross 1 was considered to indicate a statistically significantly different.

\section{RESULTS}

\section{Demographic and Baseline Characteristics of Study Population}

The study flowchart is shown in Fig. 1. We surveyed a total of 301,331 nurses from 1248 hospitals across China during the study period. We excluded 44,491 nurses whose work was unrelated to insulin injection, 28,385 nurses who had not performed insulin injection-related duties within the preceding year, and 637 nurses because of other causes. A total of 227,818 nurses were eligible for the study. After exclusion of 4450 nurses because of incomplete

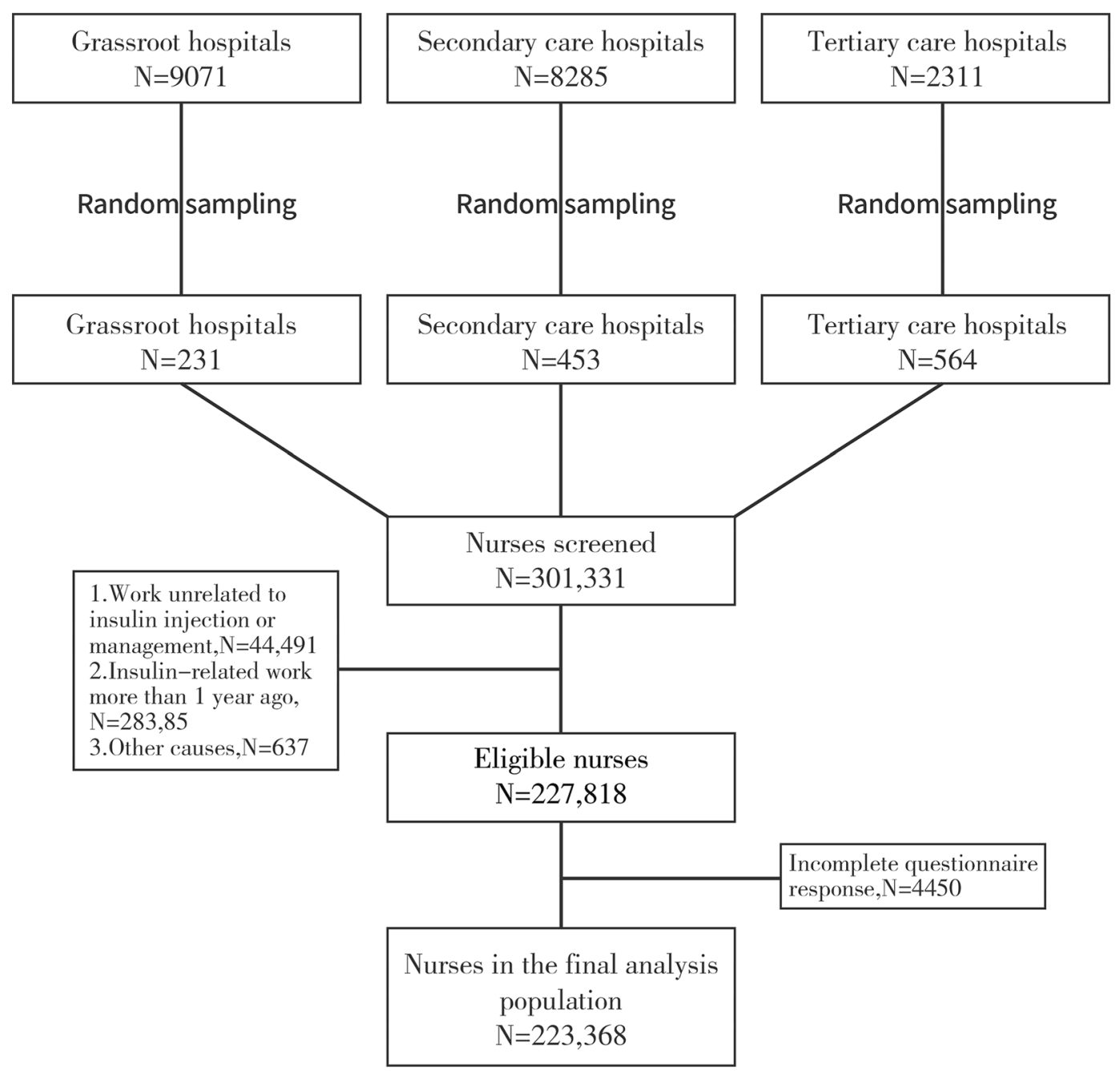

Fig. 1 Study flowchart 
questionnaire response, 223,368 nurses were included in the current cross-sectional study. The demographic and baseline variables of the study nurses are shown in Table 1 . They included 60,472 nurses (27.07\%), 106,107 (47.50\%), and 49,130 (22.0\%) nurses-in-charge with a mean age of $30.7 \pm 6.4$ years and median (Q1, Q3) duration of work experience of 7 years (4, 11). In addition, 25,289 (11.32\%) nurses were certified diabetes nurses and 13,912 (6.23\%) nurses worked at an endocrinology department. Most nurses $(87.89 \%)$ came from tertiary care hospitals, $11.40 \%$ from secondary care hospitals, and $0.71 \%$ from primary care clinics. A total of $155,032(69.14 \%)$ nurses received a bachelor's degree and 62,432 (27.95\%) nurses graduated from junior colleges.

\section{Insulin Injection Knowledge Scores of Nurses}

The mean knowledge score of the study population was $13.70 \pm 3.30$ and $20.91 \%$ of the nurses achieved a good knowledge score, $43.90 \%$ achieved a satisfactory knowledge score, and $35.19 \%$ had a poor knowledge score (Table 2). The mean score of conceptual knowledge mastery was $2.59 \pm 0.63$, the mean score of procedural knowledge mastery was $7.15 \pm 1.97$, and the mean factual knowledge mastery score was $2.93 \pm 1.19$. Less than $50 \%$ of the nurses answered seven items correctly in the questionnaire including correct interval between two injections at the same site $(16.37 \%)$, what type of insulin is Aspart $(38.41 \%)$, when to inject short-acting insulin $(45.71 \%)$, injection site management post withdrawal of insulin pen needle (38.93\%), mixing method for premixed insulin $(43.06 \%)$, proper insulin needle disposal after injection $(47.97 \%)$, and management of hypoglycemia (49.40\%) (Table 3).

\section{Insulin Injection Attitude Scores}

In addition, the mean attitude score was $17.18 \pm 2.69$ for the study nurses; $75.25 \%$ nurses achieved a good attitude score, another $21.60 \%$ achieved a satisfactory attitude score,
Table 1 Demographic and baseline characteristics of the study nurses

\begin{tabular}{ll}
\hline Variables & $\boldsymbol{N}=\mathbf{2 2 3 , 3 6 8}$ \\
\hline Female sex, $n$ (\%) & $217,199(97.24)$ \\
Age, years & \\
Mean (SD) & $30.74(6.41)$ \\
Range & 18,70 \\
$<25$ & $31,818(14.24)$ \\
$25-30$ & $78,481(35.14)$ \\
$30-35$ & $62,092(27.80)$ \\
$\geq 35$ & $50,977(22.82)$ \\
Education, $n$ (\%) & \\
Technical secondary school & $3779(1.69)$ \\
Junior college & $62,432(27.95)$ \\
Bachelor & $155,032(69.41)$ \\
Master or above & $2125(0.95)$ \\
Work experience, years & 8.88 \\
Median (Q1, Q3) & $7(4,11)$ \\
$<4$ & $52,186(23.36)$ \\
$4-7$ & $48,352(21.65)$ \\
$7-11$ & $58,934(26.38)$ \\
$\geq 11$ & $63,896(28.61)$ \\
\hline
\end{tabular}

Levels of nurses, $n$ (\%)

Nurse

$60,472(27.07)$

Senior nurse

$106,107(47.50)$

Nurse-in-charge

$49,130(22.00)$

Associate chief nurse

$6870(3.08)$

Chief nurse

$789(0.35)$

Certified diabetes nurse

Yes

$25,289(11.32)$

Positions held, $n$ (\%)

Head nurse

$15,753(7.05)$

Clinical nurse

206,986 (92.67)

Diabetes educator

$629(0.28)$

Number of beds at department 
Table 1 continued

\begin{tabular}{ll}
\hline Variables & $\boldsymbol{N}=\mathbf{2 2 3 , 3 6 8}$ \\
\hline Median (Q1, Q3) & $46(34,58)$ \\
$<35$ & $57,791(25.87)$ \\
$35-45$ & $42,132(18.86)$ \\
$45-60$ & $70,892(31.74)$ \\
$\geq 60$ & $52,553(23.53)$ \\
Hospital setting & \\
Primary care & $1576(0.71)$ \\
Secondary care & $25,465(11.40)$ \\
Tertiary care & $196,327(87.89)$ \\
Department affiliations & \\
ICU & $18,898(8.46)$ \\
Pediatrics & $3357(1.50)$ \\
Ob/Gyn & $13,264(5.94)$ \\
Emergency & $10,503(4.70)$ \\
Outpatient & $1432(0.64)$ \\
Endocrinology & $13,912(6.23)$ \\
Non-endocrinology & $71,368(31.95)$ \\
Others & $29,361(13.14)$ \\
Surgery & $61,273(27.43)$ \\
\hline
\end{tabular}

and merely $3.15 \%$ had a poor attitude score (Table 2). Most nurses considered that insulin injection technique was very important $(75.43 \%)$ or rather important $(17.76 \%)$ for plasma glucose control and the majority of the nurses felt that they could inject insulin very properly $(41.35 \%)$ or rather properly $(36.0 \%)$ (Table 4). In addition, $46.44 \%$ of the nurses were very concerned or rather concerned $(29.06 \%)$ about the feeling of patients with diabetes receiving insulin injection. Furthermore, $53.24 \%$ of the nurses were very concerned or rather concerned $(24.39 \%)$ about needle reuse by patients with diabetes.
Table 2 Overall scores of insulin injection knowledge, attitudes, and practices among nurses

\begin{tabular}{|c|c|}
\hline Variables & \\
\hline Knowledge sco & \\
\hline Mean (SD) & $13.70(3.30)$ \\
\hline Range & 1,21 \\
\hline Score categor & \\
\hline Good & $46,697(20.91)$ \\
\hline Satisfactory & $98,065(43.90)$ \\
\hline Poor & $78,606(35.19)$ \\
\hline Mastery of con & \\
\hline Mean (SD) & $2.59(0.63)$ \\
\hline Range & 0,3 \\
\hline Mastery of pro & \\
\hline Mean (SD) & $7.15(1.97)$ \\
\hline Range & 0,11 \\
\hline Mastery of fact & \\
\hline Mean (SD) & $2.93(1.19)$ \\
\hline Range & 0,5 \\
\hline Attitude scores & \\
\hline Mean (SD) & $17.18(2.69)$ \\
\hline Range & 4,20 \\
\hline Score categor & \\
\hline Good & $156,229(75.25)$ \\
\hline Satisfactory & $44,837(21.60)$ \\
\hline Poor & $6549(3.15)$ \\
\hline Practice scores & \\
\hline Mean (SD) & $83.03(8.16)$ \\
\hline Range & 21,90 \\
\hline Score categor & \\
\hline Good & $187,791(90.45)$ \\
\hline Satisfactory & $17,997(8.67)$ \\
\hline Poor & $1827(0.88)$ \\
\hline
\end{tabular}


Table 3 Insulin injection knowledge in nurses

\begin{tabular}{ll}
\hline Variables & $N(\%)$ \\
\hline
\end{tabular}

1. What type of insulin is insulin Aspart?

Long-acting insulin

22,970

(10.28)

Short-acting insulin

97,914

(43.84)

Rapid-acting insulin

85,802

(38.41)

Intermediate-acting insulin

2. Time of injection of short-acting insulin

After meal

2439 (1.09)

$30 \mathrm{~min}$ before meal

102,097

(45.71)

5-10 min before meal

Immediately before meal

56,629

3. Correct storage temperature of unopened insulin

$$
\begin{array}{lc}
10-15{ }^{\circ} \mathrm{C} & 5775(2.59) \\
15-30{ }^{\circ} \mathrm{C} & 6673(2.99) \\
2-8{ }^{\circ} \mathrm{C} & 208,546 \\
& (93.36) \\
<0{ }^{\circ} \mathrm{C} & 2374(1.06)
\end{array}
$$

4. How long is insulin placed at room temperature before injection after it is taken out from the refrigerator?

$$
\begin{array}{lc}
15 \mathrm{~min} & 44,747 \\
& (20.03) \\
30 \mathrm{~min} & 171,131 \\
& (76.61) \\
45 \mathrm{~min} & 660(0.30) \\
60 \mathrm{~min} & 6830(3.06)
\end{array}
$$

5. How long can an opened vial of insulin remain at room temperature?

15 days

16,906

(7.57)
Table 3 continued

\begin{tabular}{lc}
\hline Variables & $\boldsymbol{N}(\%)$ \\
\hline 30 days & 199,378 \\
& $(89.26)$ \\
45 days & $3005(1.35)$ \\
60 days & $4079(1.83)$
\end{tabular}

6. The safest needle entry length

$4 \mathrm{~mm}$ and $6 \mathrm{~mm}$

186,266

$4 \mathrm{~mm}$ and $8 \mathrm{~mm}$

$5 \mathrm{~mm}$ and $6 \mathrm{~mm}$

$5 \mathrm{~mm}$ and $8 \mathrm{~mm}$

4636 (2.08)

7. Which type of skin disinfectant should be used for insulin injection?

Anerdian skin disinfectant

$6171(2.76)$

$70-80 \%$ ethanol

210,191

(94.10)

Iodophor

$5696(2.55)$

Chlorine disinfectant

$1310(0.59)$

8. Appropriate site for insulin injections

Abdomen

221,417

(99.13)

Lateral thigh

193,877

(86.80)

Superolateral buttocks

169,201

(75.75)

Lateral arm

205,746

(92.11)

9. Rate of absorption of insulin according to injection site (rapid to slow)

Thigh, abdomen, upper arm, buttocks 3636 (1.63)

Abdomen, upper arm, thigh, buttocks $\quad 182,832$

Abdomen, buttocks, upper arm, thigh $\quad 26,327$

(11.79) 
Table 3 continued

\begin{tabular}{ll}
\hline Variables & $\boldsymbol{N}(\%)$ \\
\hline Upper arm, abdomen, thigh, buttocks & 10,573 \\
& $(473)$
\end{tabular}

10. The minimal distance of injection site from the last injection site

$\begin{array}{cc}1 \mathrm{~cm} & 114,130 \\ & (51.10) \\ 2 \mathrm{~cm} & 67,619 \\ & (30.27) \\ 3 \mathrm{~cm} & 21,268 \\ & (9.52) \\ 4 \mathrm{~cm} & 20,351 \\ & (9.11)\end{array}$

11. Interval between two injections at the same site

1 week

162,632

(72.81)

2 weeks

22,449

(10.05)

3 weeks

$1725(0.77)$

4 weeks

36,562

(16.37)

12. The skin is pinched during insulin injection between

Thumb and ring finger

$7317(3.28)$

Thumb and middle finger

18,167

Thumb, middle finger and index finger

187,046

(83.74)

All five fingers

10,838

13. Entry angle of $4 \mathrm{~mm}$ or $5 \mathrm{~mm}$ needle

\begin{tabular}{cc}
$30^{\circ}$ & 19,606 \\
& $(8.78)$ \\
$45^{\circ}$ & 17,018 \\
& $(7.62)$ \\
$60^{\circ}$ & $4226(1.89)$ \\
$90^{\circ}$ & 182,518 \\
& $(81.71)$ \\
\hline
\end{tabular}

Table 3 continued

\begin{tabular}{lc}
\hline Variables & $N(\%)$ \\
\hline $\begin{array}{l}\text { 14. Entry angle of } \geq 6 \mathrm{~mm} \text { needle (apart from pinching } \\
\text { the skin) } \\
15^{\circ}\end{array}$ & 17,034 \\
& $(7.63)$ \\
$30^{\circ}$ & 25,624 \\
& $(11.47)$ \\
$45^{\circ}$ & 164,302 \\
& $(73.56)$ \\
$60^{\circ}$ & 16,408 \\
& $(7.35)$
\end{tabular}

15. How long should the needle stay after insulin pen injection?

$2-3 s$

21,015

$6-9 s$

13,495

(6.04)

$\geq 10 \mathrm{~s}$

186,450

(83.47)

No

2408 (1.08)

16. Insulin injection-associated complications

Lipohypertrophy or lipoatrophy

207,025

(92.68)

Infections

196,579

(88.01)

Pain

197,331

(88.34)

Bleeding or congestion

200,912

(89.95)

17. Proper insulin pen needle disposal method after injection

Recap the needle with a single hand and

145,972 dispose the needle in the sharp container

(65.35)

Recap the needle and dispose the needle in

181,819 the sharp container

(81.40) 
Table 3 continued

\begin{tabular}{lc}
\hline Variables & $N(\%)$ \\
\hline $\begin{array}{ll}\text { Remove needle using a needle remover or } & 204,082 \\
\text { tweezers and dispose the needle in the } & (91.37) \\
\text { sharp container } & \\
\text { Recap the needle and leave the needle in } & 205,294 \\
\text { the pen } & (91.91)\end{array}$
\end{tabular}

18. After withdrawal of insulin pen needle, the injection site should

Be pressed with dry cotton swab

Be pressed with alcohol cotton swab

$2773(1.24)$

Be pressed with fingers

$940(0.42)$

Not be pressed

86,960

(38.93)

19. Incorrect mixing method for insulin

Clear insulin by naked eye does not need to be mixed

\section{4,857}

If insulin is not fully mixed, mixing can be repeated

Insulin pen fill is rolled horizontally

38,569

between hands ten times and then flipped up and down ten times in $10 \mathrm{~s}$

When mixing intermediate-acting insulin and short-acting insulin, intermediateacting insulin should be taken followed by short-acting insulin

20. Wrong statement on insulin syringe

U-100 insulin syringe is only suitable for using $100 \mathrm{U} / \mathrm{mL}$ insulin

24,338

U-40 insulin syringe should not be used

53,935

for taking insulin from insulin pen fill for injection

U-40 insulin syringe can be used for taking insulin from the insulin pen fill

123,913

$\mathrm{U}-40$ insulin syringe is only suitable for

21,182

$40 \mathrm{U} / \mathrm{mL}$ insulin

(9.48)
Table 3 continued

\begin{tabular}{|c|c|}
\hline Variables & $N(\%)$ \\
\hline $\begin{array}{l}\text { 21. Which one of the following is wrong in } \\
\text { hypoglycemia? }\end{array}$ & managing \\
\hline $\begin{array}{l}\text { When hypoglycemia is suspected, plasma } \\
\text { glucose is immediately tested to ascertain } \\
\text { diagnosis. If plasma glucose cannot be } \\
\text { measured, treat the patient as having } \\
\text { hypoglycemia }\end{array}$ & $\begin{array}{l}70,562 \\
(31.59)\end{array}$ \\
\hline $\begin{array}{l}5 \% \text { or } 10 \% \text { glucose can be given } \\
\text { intravenously in conscious patients }\end{array}$ & $\begin{array}{l}110,337 \\
(49.40)\end{array}$ \\
\hline $\begin{array}{l}15-20 \text { g candy (glucose preferred) can be } \\
\text { given orally in conscious patients }\end{array}$ & $\begin{array}{l}12,133 \\
(5.43)\end{array}$ \\
\hline $\begin{array}{l}20 \mathrm{~mL} 50 \% \text { glucose can be given by } \\
\text { intravenous injection in conscious } \\
\text { patients }\end{array}$ & $\begin{array}{l}30,336 \\
(13.58)\end{array}$ \\
\hline
\end{tabular}

Correct answer is in italics

Moreover, $42.77 \%$ of the nurses felt very confident or rather confident $(32.36 \%)$ that they could educate patients about insulin injection and $41.73 \%$ of the nurses very much wanted or rather wanted $(25.55 \%)$ to receive formal training on insulin injection.

\section{Insulin Injection Practice Scores}

The mean practice score of the study population was $83.03 \pm 8.16$. Most nurses (90.45\%) achieved a good practice score, $8.67 \%$ had a satisfactory practice score, and only $0.88 \%$ had a poor practice score (Table 2). Most nurses always $(74.55 \%)$ or often $(18.66 \%)$ washed their hands before injection and $58.86 \%$ of the nurses always or often $(22.30 \%)$ left the unopened vial or insulin pen fill at room temperature for at least $30 \mathrm{~min}$ (Table 5). Most nurses always $(81.76 \%)$ or often $(13.80 \%)$ verified name, clarity, expiration date, and remaining volume of insulin in the insulin pen fill before injection and $82.34 \%$ of the nurses always or often 
Table 4 Insulin injection attitudes among nurses

\begin{tabular}{ll}
\hline Variables & $N(\%)$ \\
\hline
\end{tabular}

1. Do you think that insulin injection technique is important for plasma glucose control?

$\begin{array}{ll}\text { Not at all } & 1332(0.64) \\ \text { A little bit } & 4484(2.16) \\ \text { Somewhat } & 8323(4.01) \\ \text { Rather } & 36,878(17.76) \\ \text { Very } & 156,598(75.43)\end{array}$

2. Do you think that you can inject insulin properly?

$\begin{array}{ll}\text { Not at all } & 1309(0.63) \\ \text { A little bit } & 7568(3.65) \\ \text { Somewhat } & 38,146(18.37) \\ \text { Rather } & 74,734(36.00) \\ \text { Very } & 85,858(41.35)\end{array}$

3. How concerned are you about the feeling of diabetic patients at the time of insulin injection?

$\begin{array}{ll}\text { Not at all } & 1076(0.52) \\ \text { A little bit } & 9562(4.61) \\ \text { Somewhat } & 40,233(19.38) \\ \text { Rather } & 60,328(29.06) \\ \text { Very } & 96,416(46.44)\end{array}$

4. How concerned are you about needle reuse by diabetic patients?

Not at all $3935(1.90)$

A little bit $9485(4.57)$

Somewhat $33,022(15.91)$

Rather $50,638(24.39)$ Very $110,535(53.24)$

5. Are you confident that you can teach diabetic patients to correctly inject insulin?
Not at all
$1418(0.68)$
A little bit
$8915(4.29)$
Somewhat
$41,298(19.89)$
Rather
$67,193(32.36)$

Table 4 continued

\begin{tabular}{|c|c|}
\hline Variables & $N(\%)$ \\
\hline Very & $88,791(42.77)$ \\
\hline \multicolumn{2}{|c|}{$\begin{array}{l}\text { 6. Do you want to receive formal training on insulin } \\
\text { injection? }\end{array}$} \\
\hline Not at all & $2611(1.26)$ \\
\hline A little bit & $15,461(7.45)$ \\
\hline Somewhat & $49,868(24.02)$ \\
\hline Rather & $53,043(25.55)$ \\
\hline Very & $86,632(41.73)$ \\
\hline
\end{tabular}

(12.87\%) fully mixed premixed insulin before injection while $78.98 \%$ of the nurses always or often (12.10\%) pushed out air bubbles before injection. In addition, $67.22 \%$ of the nurses always or often (19.77\%) asked about the site of last injection and $67.38 \%$ of the nurses always or often (19.97\%) asked about tenderness of the injection site while $73.01 \%$ of the nurses always or often $(12.62 \%)$ used new needles in each injection and $69.51 \%$ of the nurses always or often $(21.54 \%)$ shifted the injection site during each injection. Furthermore, $71.40 \%$ of the nurses always or often (15.96\%) recapped or removed the needle using the tweezers or needle remover and placed the needle and syringe in a safe container after injection. Additionally, $87.96 \%$ of the nurses always or often (9.2\%) asked about meal preparation when giving mealtime insulin while $80.51 \%$ of the nurses always or often $(14.72 \%)$ paid attention to plasma glucose levels in patients with diabetes.

\section{Correlation Among Insulin Injection Knowledge, Attitude, and Practice Scores Among Nurses}

We analyzed the correlation among insulin injection knowledge, attitude, and practice scores among nurses. Pearson correlation analysis showed significant correlation between the 
Table 5 Survey of insulin injection practices among nurses

\begin{tabular}{ll}
\hline Variables & $N(\%)$ \\
\hline
\end{tabular}

1. Wash hand before injection

$\begin{array}{ll}\text { Never } & 679(0.33) \\ \text { Occasionally } & 3711(1.79) \\ \text { Sometimes } & 9695(4.67) \\ \text { Often } & 38,745(18.66) \\ \text { Always } & 154,785(74.55)\end{array}$

2. Unopened vial of insulin or insulin pen fill is left at room temperature for $30 \mathrm{~min}$ after being taken out from the refrigerator

$\begin{array}{ll}\text { Never } & 5292(2.55) \\ \text { Occasionally } & 9746(4.69) \\ \text { Sometimes } & 24,078(11.60) \\ \text { Often } & 46,298(22.30) \\ \text { Always } & 122,201(58.86)\end{array}$

3. Name, character, expiration date, and remaining volume of insulin in the insulin pen fill is checked before injection

Never

Occasionally $706(0.34)$

Sometimes

$$
2237 \text { (1.08) }
$$$$
6284(3.03)
$$

Often $28,646(13.80)$

Always $169,742(81.76)$

4. Full mixing is done before injection of premixed insulin

$\begin{array}{ll}\text { Never } & 1277(0.62) \\ \text { Occasionally } & 2174(1.05) \\ \text { Sometimes } & 6485(3.12) \\ \text { Often } & 26,720(12.87) \\ \text { Always } & 170,959(82.34)\end{array}$

5. Push out air bubbles in the insulin pen or syringe before injecting insulin

Never

4837 (2.33)

Occasionally

$4290(2.07)$

Sometimes

$9408(4.53)$
Table 5 continued

\begin{tabular}{ll}
\hline Variables & $\boldsymbol{N}(\%)$ \\
\hline Often & $25,112(12.10)$ \\
Always & $163,968(78.98)$
\end{tabular}

6. The volume button in the insulin pen is set to the right dose before use

$\begin{array}{ll}\text { Never } & 1485(0.72) \\ \text { Occasionally } & 1232(0.59) \\ \text { Sometimes } & 2863(1.38) \\ \text { Often } & 13,927(6.71) \\ \text { Always } & 188,108(90.60)\end{array}$

7. Ask about meal preparation when giving mealtime insulin

Never

$$
506(0.24)
$$

Occasionally

$1260(0.61)$

Sometimes

4137 (1.99)

Often

$19,100(9.20)$

Always

$182,612(87.96)$

8. Pay attention to plasma glucose levels in patients

$\begin{array}{ll}\text { Never } & 437(0.21) \\ \text { Occasionally } & 1682(0.81) \\ \text { Sometimes } & 7786(3.75) \\ \text { Often } & 30,556(14.72) \\ \text { Always } & 167,154(80.51)\end{array}$

9. Ask about site of last injection

$\begin{array}{ll}\text { Never } & 1619(0.78) \\ \text { Occasionally } & 5529(2.66) \\ \text { Sometimes } & 19,854(9.56) \\ \text { Often } & 41,046(19.77) \\ \text { Always } & 139,567(67.22)\end{array}$

10. Ask about injection site tenderness prior to injection

Never

1304 (0.63)

Occasionally

5099 (2.46)

Sometimes

$19,869(9.57)$

Often

41,452 (19.97) 
Table 5 continued

\begin{tabular}{ll}
\hline Variables & $N(\%)$ \\
\hline Always & $139,891(67.38)$
\end{tabular}

11. Injection site is shifted during each injection

$\begin{array}{ll}\text { Never } & 1003(0.48) \\ \text { Occasionally } & 3226(1.55) \\ \text { Sometimes } & 14,359(6.92) \\ \text { Often } & 44,717(21.54) \\ \text { Always } & 144,310(69.51)\end{array}$

12. Prior to injection, injection site is carefully examined for skin induration or swelling

$\begin{array}{ll}\text { Never } & 3220(1.55) \\ \text { Occasionally } & 6425(3.09) \\ \text { Sometimes } & 20,880(10.06) \\ \text { Often } & 44,260(21.32) \\ \text { Always } & 132,830(63.98)\end{array}$

13. The injection site is disinfected and becomes dry before injection

$\begin{array}{ll}\text { Never } & 512(0.25) \\ \text { Occasionally } & 1747(0.84) \\ \text { Sometimes } & 7048(3.39) \\ \text { Often } & 35,151(16.93) \\ \text { Always } & 163,157(78.59)\end{array}$

14. Skin pinching technique or entry at an angle of $45^{\circ}$ is done when using $\geq 6 \mathrm{~mm}$ insulin pen or syringe

$\begin{array}{ll}\text { Never } & 2874(1.38) \\ \text { Occasionally } & 3399(1.64) \\ \text { Sometimes } & 14,080(6.78) \\ \text { Often } & 46,653(22.47) \\ \text { Always } & 140,609(67.73)\end{array}$

15. Insulin is injected despite injection site skin induration or swelling

Never $167,131(80.50)$

Occasionally 8956 (4.31)

Sometimes $2914(1.40)$
Table 5 continued

\begin{tabular}{ll}
\hline Variables & $\boldsymbol{N}(\%)$ \\
\hline Often & $4703(2.27)$ \\
Always & $23,911(11.52)$
\end{tabular}

16. New needle is used each time insulin is injected

$\begin{array}{ll}\text { Never } & 1394(0.67) \\ \text { Occasionally } & 8535(4.11) \\ \text { Sometimes } & 19,905(9.59) \\ \text { Often } & 26,208(12.62) \\ \text { Always } & 151,573(73.01)\end{array}$

17. Needle remains subcutaneously for at least $10 \mathrm{~s}$ after insulin is injected

$\begin{array}{ll}\text { Never } & 1574(0.76) \\ \text { Occasionally } & 2242(1.08) \\ \text { Sometimes } & 6159(2.97) \\ \text { Often } & 22,287(10.73) \\ \text { Always } & 175,353(84.46)\end{array}$

18. After insulin is injected, the needle is recapped or is removed using tweezers or needle remover and the needle and syringe are placed in a safe container

\begin{tabular}{ll} 
Never & $5773(2.78)$ \\
Occasionally & $6313(3.04)$ \\
Sometimes & $14,148(6.81)$ \\
Often & $33,138(15.96)$ \\
Always & $148,243(71.40)$ \\
\hline
\end{tabular}

knowledge score and the attitude score $(r=0.29 ; P<0.001)$ and between the knowledge score and the practice score $(r=0.27$; $P<0.001$ ) (Table 6 and Supplementary Tables 1 and 2). Furthermore, the attitude score exhibited significant correlation with the practice score $(r=0.56 ; P<0.001)$. These findings were further confirmed by our Spearman correlation analysis. Our multivariate analysis additionally revealed that nurses with higher knowledge 


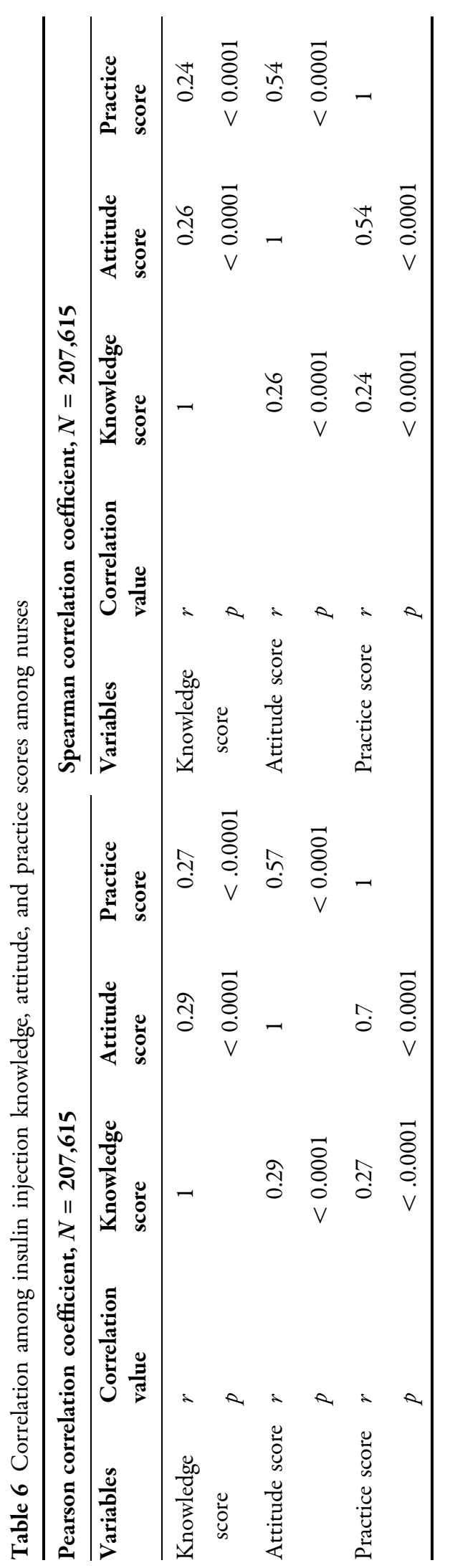

scores were also more likely to have higher attitude scores and practice scores (Table 7) and nurses with higher attitude scores were also more likely to have higher practice scores.

Our multivariate analysis further showed that male gender was a significant risk for lower knowledge score (OR 1.625; 95\% CI 1.541, 1.714) and attitude score (OR 1.021, 95\% CI $0.963,1.082$ ) (Table 7 ). Age $<25$ years was associated with a higher knowledge score versus age $\geq 35$ years (OR 0.734; 95\% CI 0.692, 0.778) while age between 30 and 35 years was a significant risk for lower attitude score (OR 1.116; $95 \%$ CI $1.067,1.168)$ and practice score versus age $\geq 35$ years (OR 1.243; 95\% CI 1.157, 1.334). In addition, nurses with lower educational levels were in general more likely to have a poor knowledge score but were more likely to have a higher attitude score and a higher practice score. Furthermore, nurses with a shorter work history were more likely to have a poor attitude score and a poor practice score than nurses with a longer work history. Nurses at lower professional ranks were less likely to have a poor attitude score compared with higher level nurses and nurses were more likely to have a poor knowledge score compared to chief nurses (OR $1.708 ; 95 \%$ CI 1.467, 1.988). Furthermore, clinical nurses were more likely than diabetes educators to have a lower knowledge score (OR 1.659; 95\% CI 1.346, 2.044) and a lower attitude score (OR 1.392; 95\% CI 1.070, 1.811). Moreover, non-certified diabetes nurses were less likely to have a poor knowledge score (OR $0.735 ; 95 \%$ CI $0.715,0.756)$ but more likely to have a poor attitude score compared to certified diabetes specialist nurses (OR 1.136; 95\% CI $1.098,1.175)$. Compared to nurses in the primary care setting, nurses in the secondary care setting were more likely to have a poor knowledge score (OR 1.304; 95\% CI 1.165, 1.459), but they (OR 0.889; 95\% CI 0.777, 1.016) and nurses in tertiary care setting (OR 0.827 ; $95 \%$ CI $0.725,0.943)$ were less likely to have a lower attitude score. Compared to nurses from endocrinology department, nurses from nonendocrinology departments were more likely to have a poor knowledge, attitude, and practice score. Emergency nurses had the lowest 
Table 7 Multivariate logistic regression analysis for risk factors of poor insulin injection knowledge, attitude, and practice scores among nurse

\section{Variables}

Gender

Male vs. female

Age, years

$$
\begin{aligned}
& <25 \text { vs. } \geq 35 \\
& 25-30 \text { vs. } \geq 35 \\
& 30-35 \text { vs. } \geq 35
\end{aligned}
$$

Education

Technical secondary school vs. master or above

Junior college vs. master or above

Bachelor vs. master or above

Levels of nurse

Nurse vs. chief nurse

Senior nurse vs. chief nurse

Nurse-in-charge vs. chief nurse

Associate chief nurse vs. chief nurse

Certified diabetes nurse

No vs. yes

Positions held

Head nurse vs. diabetes educator

Clinical nurse vs. diabetes educator

Number of beds

$$
\begin{aligned}
& <35 \text { vs. } \geq 60 \\
& 35-45 \text { vs. } \geq 60 \\
& 45-60 \text { vs. } \geq 60
\end{aligned}
$$

1.6251

$\begin{array}{llllll}0.734 & 0.692,0.778 & 1.046 & 0.979,1.118 & 1.064 & 0.959,1.180 \\ 0.930 & 0.886,0.975 & 1.024 & 0.969,1.082 & 1.122 & 1.029,1.223 \\ 1.015 & 0.978,1.054 & 1.116 & 1.067,1.168 & 1.243 & 1.157,1.334\end{array}$

$1.889 \quad 1.682,2.120 \quad 0.920 \quad 0.793,1.067 \quad 0.695 \quad 0.562,0.859$

$1.350 \quad 1.226,1.486 \quad 0.834 \quad 0.733,0.948 \quad 0.599 \quad 0.500,0.718$

$\begin{array}{lllllll}1.078 & 0.981,1.185 & 0.830 & 0.731,0.943 & 0.637 & 0.533,0.760\end{array}$

$$
\begin{array}{llllll}
1.708 & 1.467,1.988 & 0.889 & 0.670,1.179 & 1.301 & 0.794,2.132 \\
1.174 & 1.011,1.364 & 0.905 & 0.683,1.200 & 1.476 & 0.902,2.416 \\
0.815 & 0.703,0.946 & 0.920 & 0.694,1.220 & 1.596 & 0.974,2.615 \\
0.784 & 0.672,0.915 & 0.719 & 0.527,0.980 & 1.220 & 0.710,2.099
\end{array}
$$

$0.735 \quad 0.715,0.756 \quad 1.136 \quad 1.098,1.175 \quad 0.934 \quad 0.887,0.983$

$3.2562 .635,4.023$

$1.659 \quad 1.346,2.044 \quad 1.392 \quad 1.070,1.811 \quad 0.840 \quad 0.583,1.209$

$$
\begin{array}{llllll}
1.016 & 0.988,1.045 & 0.933 & 0.903,0.965 & 0.874 & 0.830,0.921 \\
0.935 & 0.910,0.961 & 0.901 & 0.873,0.931 & 0.931 & 0.885,0.978 \\
0.959 & 0.936,0.982 & 0.938 & 0.913,0.965 & 0.970 & 0.929,1.012
\end{array}
$$

Duration of employment, years

$$
\begin{aligned}
& <4 \text { vs. } \geq 11 \\
& 4-7 \text { vs. } \geq 11 \\
& 7-11 \text { vs. } \geq 11
\end{aligned}
$$

$\begin{array}{llllll}0.840 & 0.798,0.884 & 1.504 & 1.419,1.595 & 1.363 & 1.246,1.492 \\ 0.958 & 0.916,1.002 & 1.330 & 1.263,1.401 & 1.363 & 1.259,1.475 \\ 1.024 & 0.988,1.062 & 1.237 & 1.186,1.290 & 1.247 & 1.168,1.331 \\ & & & & & \\ 1.304 & 1.165,1.459 & 0.889 & 0.777,1.016 & 1.129 & 0.903,1.410 \\ 1.218 & 1.091,1.360 & 0.827 & 0.725,0.943 & 1.122 & 0.902,1.396\end{array}$


Table 7 continued

\begin{tabular}{|c|c|c|c|c|c|c|}
\hline \multirow[t]{2}{*}{ Variables } & \multicolumn{2}{|c|}{ Knowledge score } & \multicolumn{2}{|c|}{ Attitude score } & \multicolumn{2}{|c|}{ Practice score } \\
\hline & OR & 95\% CI & OR & $95 \% \mathrm{CI}$ & OR & 95\% CI \\
\hline \multicolumn{7}{|l|}{ Departments } \\
\hline ICU vs. surgery & 1.059 & $1.018,1.101$ & 1.327 & $1.270,1.387$ & 0.988 & $0.922,1.059$ \\
\hline Pediatrics vs. surgery & 0.946 & $0.880,1.018$ & 1.176 & $1.077,1.283$ & 0.613 & $0.523,0.719$ \\
\hline Obstetrics vs. surgery & 0.959 & $0.922,0.998$ & 1.070 & $1.022,1.120$ & 0.772 & $0.714,0.834$ \\
\hline Emergency vs. surgery & 1.171 & $1.119,1.225$ & 1.400 & $1.332,1.473$ & 1.001 & $0.926,1.082$ \\
\hline Outpatient department vs. surgery & 1.133 & $1.015,1.265$ & 0.978 & $0.825,1.159$ & 1.009 & $0.769,1.325$ \\
\hline Endocrinology vs. surgery & 0.305 & $0.290,0.320$ & 0.442 & $0.416,0.470$ & 0.725 & $0.658,0.799$ \\
\hline Internal medicine excluding endocrinology vs. surgery & 0.866 & $0.847,0.886$ & 0.990 & $0.964,1.017$ & 1.068 & $1.025,1.112$ \\
\hline Others vs. surgery & 1.044 & $1.013,1.075$ & 1.002 & $0.968,1.038$ & 1.027 & $0.973,1.084$ \\
\hline \multicolumn{7}{|l|}{ Knowledge scores } \\
\hline Good vs. poor & - & - & 0.272 & $0.263,0.281$ & 0.351 & $0.331,0.372$ \\
\hline Satisfactory vs. poor & - & - & 0.530 & $0.518,0.542$ & 0.586 & $0.566,0.607$ \\
\hline \multicolumn{7}{|l|}{ Attitude scores } \\
\hline Good vs. poor & - & - & - & - & 0.049 & $0.046,0.051$ \\
\hline Satisfactory vs. poor & - & - & - & - & 0.338 & $0.320,0.357$ \\
\hline
\end{tabular}

knowledge and practice scores while ICU nurses had lower attitude and practice scores.

\section{DISCUSSION}

Our study revealed some deficiencies in insulin injection knowledge, attitudes, and practices, which was similar to the previous studies [11-17]. The study showed that only $64.81 \%$ of the nurses achieved a good or satisfactory knowledge score, which was in line with $66.2 \%$ of nurses at a tertiary care hospital in Hunan province, but lower than $83.5 \%$ of nurses at another tertiary care hospital in Guangdong province, suggesting that the insulin injection knowledge levels of nurses may differ across regions in China. In addition, we found that nurses at secondary care hospitals had the lowest overall score, indicating that secondary care nurses may be a weak link in insulin injection management. This could be due to the point-topoint coupling of primary care clinics and tertiary care hospitals in China. Nurses in the primary care setting had the highest overall score which may be because community hospital nurses carry out the job of chronic disease management and nurses have more opportunities to educate patients with diabetes on injection. Moreover, most (93.77\%) of the nurses in this study were from non-endocrinology departments. The result showed that diabetes educators had higher overall score than other types of nurses, indicating that training on insulin injection knowledge should focus more on non-diabetes clinic nurses.

It has been shown that nurses showed deficiencies in diabetes and diabetes care knowledge [18]. Our study further revealed that approximately one-third of the nurses surveyed had a poor insulin injection knowledge score and the deficits were particularly acute in 
injection site management and insulin needle disposal and hypoglycemia management. Our study revealed that approximately two in ten nurses $(22.37 \%)$ did not show much concern about needle reuse by diabetic patients. A survey of 380 patients with diabetes from 20 centers in China showed that the rate of single needle reuse was high in patients with diabetes and needle reuse significantly correlated with lipohypertrophy $(r=0.426, \quad P=0.000) \quad$ [19]. Song et al. also showed that Chinese patients with diabetes had a higher needle reuse rate than patients in other countries (78\% vs. $48 \%$ ) [20]. It remains to be investigated whether greater nurse concern about needle reuse by patients with DM lowers the rate of single needle reuse in patients with DM. These issues are important barriers for effective and safe management of insulin injection. We speculate that the poor knowledge scores are due to inadequate training and not being up to date about current guidelines on diabetes. Dai et al. found that only $56.87 \%$ nurses at tertiary care institutions knew about the most recent guideline for insulin injection in patients with diabetes [21], highlighting the need for workplace-based learning and training based on the latest guidelines to further enhance insulin injectionrelated knowledge, attitude, and practice.

The current study showed that $96.85 \%$ of nurses achieved a good or satisfactory attitude score, indicating an overall positive attitude among nurses in China. Considering the relatively low knowledge scores of the nurses, it remains possible that the nurses may overestimate their attitudes and practices in self-evaluation. However, this is speculative given the subjective nature of the current questionnaire in the study and that no real-world practices were assessed, and no skill tests were performed. In addition, approximately one-quarter of the nurses were inadequate in confidence in proper injection, concern for the feeling of patients with diabetes, repetitive use of insulin needles, and confidence in instructing insulin injection. Approximately two in three (67.28\%) nurses felt that they need training on insulin injection. Furthermore, we found that a quarter of the nurses were not fully confident about teaching diabetic patients about correct insulin injection techniques. As mastery of insulin injection knowledge and insulin injection techniques is essential for nurses to administer insulin correctly and to educate patients adequately, our findings highlight the importance of improving nurses' insulin injection knowledge and practice and the need for patient education. In addition, patient education regarding correct and safe insulin injection practices may also be improved with increased insulin injection knowledge by nurses as patients with diabetes have a deficit in insulin injection technique $[22,23]$.

Theofanidis found that nurses had a poor compliance rate of insulin injection practices and $42.7 \%$ of the nurses did not check for air bubbles in the syringe and $89.1 \%$ of the nurses did not check the injection site for appropriateness or other possible complications [11]. In our study, approximately $90 \%$ of the nurses always or often check for air bubbles in the syringe before injection and about $85 \%$ of them carefully examined the insulin injection site before injection, indicating that nurses in China have better rates of good insulin injection practice.

The study further found significant correlation among knowledge, attitude, and practice scores of the nurses, suggesting that both knowledge and attitudes influence practices, emphasizing the importance of mastery of knowledge of proper insulin injection. To improve the levels of knowledge and attitudes that influence practices among non-endocrinology nurses, endocrinology nurses and diabetes liaison nurses could play a bigger role. A hospital diabetes management group should be established to promote standardized insulin injection procedures and centralized training and examination so that insulin injection can be provided at the same standard at different departments and across different institutions.

This is the first cross-sectional study of insulin injection knowledge, attitude, and practice among nurses at different healthcare settings across China. It uncovers certain areas of deficiencies in nurses' knowledge and practices like lack of knowledge that can be addressed to improve nurses' practices and thus diabetes care. However, this study has some 
limitations. One is that the assessment was done by the nurses themselves, which may raise the question about the objectivity of the nurses' answers. In addition, the injection techniques skills probed in the questionnaire were not verified in real-world practice. Another limitation is that we did not analyze the results of the study by healthcare settings. The study surveyed nurses from the primary, secondary, and tertiary care settings. The primary care setting has a very high proportion of chronic patients including patients with diabetes. As a result, these nurses may put more emphasis on learning insulin injection knowledge and skills, which may affect their insulin injection knowledge, attitudes, and practice scores. We will further carry out analysis of performance of nurses in these areas in the future to see how nurses from different healthcare settings differ in insulin injection knowledge, attitudes, and practice scores and provide recommendations on improving their insulin injection knowledge, attitudes, and practice abilities through continuing education and standardized training.

\section{CONCLUSIONS}

Less than two-thirds of the nurses surveyed achieved a good or satisfactory knowledge score while more than $95 \%$ of them achieved a good or satisfactory attitude or practice score. Our study highlights the need for workplace-based learning and training to further enhance insulin injection-related knowledge, attitude, and practice.

\section{ACKNOWLEDGEMENTS}

Thanks to all the experts and staff who participated in the project. Thanks to Chinese Nursing Association and Becton Dickinson (BD) for their contribution.

Author's Contributions. Xinjuan $\mathrm{Wu}$ and Fang Zhao contributed to the study conception and design. All authors collected the data and performed the data analysis. All authors contributed to the interpretation of the data and the completion of figures and tables. All authors contributed to the drafting of the article and final approval of the submitted version.

Authorship. All named authors meet the International Committee of Medical Journal Editors (ICMJE) criteria for authorship for this article, take responsibility for the integrity of the work as a whole, and have given their approval for this version to be published.

Disclosures. Xinjuan Wu, Fang Zhao, Mingxia Zhang, Li Yuan, Yining Zheng, Jin Huang, Yangxi Li and Caihong Li declare that they have nothing to disclose.

Funding. This study and journal's Rapid Service Fee was funded by BD. No healthcare professional received payment for participating in the study, and no payments were given to any author for the publication of this article.

Compliance with Ethics Guidelines. The study protocol ethical approval was granted by the ethics committee of China-Japan Friendship Hospital (No. 2019-68-K47). All procedures performed in studies involving human participants were in accordance with the Helsinki Declaration of 1964, and its later amendments. All study subjects provided written informed consent prior to enrollment.

Data Availability. The datasets used and/or analyzed during the current study are available from the corresponding author on reasonable request.

Open Access. This article is licensed under a Creative Commons Attribution-NonCommercial 4.0 International License, which permits any non-commercial use, sharing, adaptation, distribution and reproduction in any medium or format, as long as you give appropriate credit to the original author(s) and the source, provide a link to the Creative Commons licence, and indicate if changes were made. The images or other third party material in this article are included in the article's Creative Commons 
licence, unless indicated otherwise in a credit line to the material. If material is not included in the article's Creative Commons licence and your intended use is not permitted by statutory regulation or exceeds the permitted use, you will need to obtain permission directly from the copyright holder. To view a copy of this licence, visit http://creativecommons.org/licenses/by$\mathrm{nc} / 4.0 /$.

\section{REFERENCES}

1. NCD Risk Factor Collaboration (NCD-RisC). Worldwide trends in diabetes since 1980: a pooled analysis of 751 population-based studies with 44 million participants. Lancet. 2016;387(10027): 1513-30.

2. Guariguata L, Whiting DR, Hambleton I, Beagley J, Linnenkamp U, Shaw JE. Global estimates of diabetes prevalence for 2013 and projections for 2035 . Diabetes Res Clin Pract. 2014;103(2):137-49.

3. IDF Diabetes Atlas. 9th Edition. 2019. https://www. d-net.idf.org/upload/resources/material/20200302_ 133351_IDFATLAS9e-final-web.pdf

4. Frid AH, Hirsch LJ, Menchior AR, Morel DR, Strauss KW. Worldwide injection technique questionnaire study: population parameters and injection practices. Mayo Clin Proc. 2016;91(9):1212-23.

5. Frid AH, Hirsch LJ, Menchior AR, Morel DR, Strauss KW. Worldwide injection technique questionnaire study: population parameters and injection practices. Mayo Clin Proc. 2016;91(9):1224-30.

6. Prieto-Sanchez LM. Hyperglycemia in-hospital management. Ther Adv Endocrinol Metab. 2011;2(1):3-7.

7. Misnikova IV, Gubkina VA, Lakeeva TS, Dreval AV. A randomized controlled trial to assess the impact of proper insulin injection technique training on glycemic control. Diabetes Ther. 2017;8(6): 1309-18.

8. Grassi G, Scuntero P, Trepiccioni R, Marubbi F, Strauss K. Optimizing insulin injection technique and its effect on blood glucose control. J Clin Transl Endocrinol. 2014;1(4):145-50.

9. Frid AH, Kreugel G, Grassi G, et al. New insulin delivery recommendations. Mayo Clin Proc. 2016;91(9):1231-55.
10. Chinese Diabetes Society. Chinese diabetes drug delivery guideline (2016). Chinese J Diabetes Mellitus. 2017;9(2):79-105. https://doi.org/10.3760/ cma.j.issn.1674-5809.2017.02.005. http://rs.yiigle. com/CN115791201702/945763.htm.

11. Theofanidis D. In-hospital administration of insulin by nurses in northern Greece: an observational study. Diabetes Spectr. 2017;30(3):175-81.

12. Robb A, Reid B, Laird EA. Insulin knowledge and practice: a survey of district nurses in Northern Ireland. Br J Community Nurs. 2017;22(3):138-45.

13. Derr RL, Sivanandy MS, Bronich-Hall L, Rodriguez A. Insulin-related knowledge among health care professionals in internal medicine. Diabetes Spectr. 2007;20(3):177-85.

14. Mushta AM. Study of insulin injection technique amongst the nursing staff. Pak J Med Sci. 2006;22(3):310-2.

15. Yacoub MI, Demeh WM, Darawad MW, Barr JL, Saleh AM, Saleh MY. An assessment of diabetes-related knowledge among registered nurses working in hospitals in Jordan. Int Nurs Rev. 2014;61(2): 255-62.

16. Adhikari S, Poudel RS, Rajbanshi L, Shrestha S. Assessment of insulin injection practice of nurses working in a tertiary healthcare center of Nepal. Nurs Res Pract. 2018;2018:9375067.

17. Wei SF, Xu P, Li YP, Wang P, Si DQ. Analysis of hidden dangers of non-endocrine insulin use and countermeasures. Nurs Pract Res. 2012;9(5):90-1.

18. Alotaibi A, Al-Ganmi A, Gholizadeh L, Perry L. Diabetes knowledge of nurses in different countries: an integrative review. Nurse Educ Today. 2016;39: 32-49.

19. Ji J, Lou Q. Insulin pen injection technique survey in patients with type 2 diabetes in mainland China in 2010. Curr Med Res Opin. 2014;30(6):1087-93.

20. Song Z, Guo X, Ji L, Huang X, Hirsch LJ, Strauss KW. Insulin injection technique in China compared with the rest of the world. Diabetes Ther. 2018;9(6): 2357-68.

21. Dai $M$, Liang $H$, Huang J. Investigation of insulin injection knowledge, belief and practice among clinical nurses from grade three general hospitals. J Nurs Sci. 2019;34(24):60-3.

22. Gentile S, Strollo F, Guarino G, Giancaterini A, Ames PRJ, Speese K, Guida P, Strauss K, on behalf of the AMDOSDI Italian Injection Technique Study Group. Factors hindering correct identification of 
unapparent lipohypertrophy. J Diab Metab Dis Contr. 2016;3:00065.

23. Gentile S, Guarino G, Giancaterini A, Guida P, Strollo F, AMD-OSDI Italian Injection Technique
Study Group. A suitable palpation technique allows to identify skin lipohypertrophic lesions in insulin treated people with diabetes. Springerplus. 2016;5: 563. 